\title{
Mortality in patients with testicular cancer: report of the Anglia and Trent testicular tumour groups
}

\author{
MATTHEW ELLIS, KAROL SIKORA
}

\begin{abstract}
The overall prognosis of patients with testicular cancer has improved dramatically over the past decade. Most patients are now treated in regional oncology centres in general hospitals. The cause of death was determined in 52 patients in the East Anglian and Trent regions who presented between 1980 and 1984. The overall mortality was $10 \cdot 8 \%$. Thirty four patients died with progressive disease, 12 of treatment related problems, two suddenly at home in between chemotherapy courses, and four of incidental causes. Reasons for treatment failure and for the deaths related to treatment were analysed and several recommendations made to reduce the death rate in this highly curable disease predominantly of young men.
\end{abstract}

\section{Introduction}

Testicular cancer has provided one of the success stories of modern oncology. The development of effective chemotherapy in the 1970s, accurate staging by new radiological techniques, and precise monitoring by sensitive tumour markers have all contributed to the dramatic improvement in prognosis for patients with this disease. ${ }^{1}$ Since 1980 these advances have been widely available outside those centres with a specialist interest in this tumour. Most patients in Britain are now treated at regional radiotherapy and oncology centres.

The past five years has continued to bring small improvements in overall outlook, but two important problems remain. Patients who fail to respond completely to aggressive treatment have little hope of salvage; and intensive therapy remains toxic, causing unpleasant side effects and some treatment related deaths. ${ }^{2}$

Though much information has come from centres with a specialist interest in this disease, ${ }^{34}$ their referral pathways result in the accrual of a highly selected group of patients. The aim of this study was to examine the cause of death in patients with testicular cancer treated in the East Anglian and Trent regions during 1980-4. Before this period many patients were referred to treatment centres in the London area. The two regions provide their cancer services through a series of radiotherapy and oncology units of varying size. No attempt has been made to concentrate specialist skills in the management of patients with this tumour within these regions, which provide health care for a large area of eastern England. We were particularly concerned with the incidence of treatment related and therefore potentially avoidable deaths in order to study the

Ludwig Institute for Cancer Research, Addenbrooke's Hospital, Cambridge CB2 2QQ

MATTHEW ELLIS, BSC, MB, clinical research fellow

KAROL SIKORA, MRCP, FRCR, director and honorary consultant in radiotherapy and oncology

Members of the testicular tumour groups were: Hugo Baillie-Johnson (Norwich); Stephen Chan (Cambridge); Hamish Cole (Northampton); Peter Corbet (Sheffield); Adrian Dixon (Cambridge); Derek Gamble (Colchester); Harold Hope-Stone(London); Walter Jackson (Norwich); Fergus Madden (Leicester); Terry Mott (Ipswich); Tim Oliver (London); Jo Ostrowski (Norwich); Donald Phillips (Southend); Bill Pratt (Colchester); Howard Smedley (Cambridge); Colin Trask (Southend); James Watson (Cambridge); Christopher Wiltshire (Ipswich)

Correspondence to: Professor K Sikora, Royal Postgraduate Medical School, Hammersmith Hospital, London W12 0HS balance between these and deaths due to persistent or recurrent tumour. Prognostic factors were not examined, as these have been well documented in a recent national study.

\section{Patients and methods}

All patients had histologically proved seminoma or teratoma of testicular origin, as defined by the British Testicular Tumour Panel ${ }^{5}$ diagnosed in 1980 to 1984 inclusive. Local cancer registries provided the names of al patients both alive and dead in whom testicular cancer was diagnosed during the study period. The notes of all patients who had died were analysed fo age at diagnosis, histological type, stage (as defined by the Royal Marsden system $){ }^{6}$ details of radiotherapy and chemotherapy, and date and cause of death. Information from clinical descriptions in the notes was supplemented by laboratory and radiological data and postmortem examination in 16 cases. Discussion with the clinician responsible provided important extra information.

\section{Results}

Four hundred and eighty patients with testicular cancer were identified in the two regions between January 1980 and December 1984. They were treated in five centres (table I). Two hundred and fifty had teratomas and 230 seminomas. Fifty two of the patients $(10 \cdot 8 \%)$ died, 16 with seminoma and 36 with teratoma (21 undifferentiated malignant teratoma, 10 trophoblastic malignant teratoma, and five intermediate malignant teratoma). Thirty fou deaths $(65 \%)$ were due to progressive disease, $12(23 \%)$ were related to treatment, two $(4 \%)$ were sudden, unexplained deaths that occurred at home during chemotherapy, and four $(8 \%)$ were due to incidental causes.

TABLE I - Distribution of testicular tumours treated in five regions

\begin{tabular}{lcccccc}
\hline & Cambridge & Sheffield & Ipswich & Leicester & Norwich & Total \\
\hline Teratomas & 77 & 82 & 10 & 42 & 39 & 250 \\
Seminomas & 78 & 65 & 23 & 27 & 37 & 230 \\
\hline Total & 155 & 147 & 33 & 69 & 76 & 480 \\
\hline
\end{tabular}

\section{DEATHS FROM PROGRESSIVE DISEASE}

Table II summarises details of the 34 patients who died with progressive disease. Twenty five patients had teratomas, which in 21 cases $(84 \%)$ wer stage IV at presentation. Fifteen patients $(60 \%)$ received cisplatin, bleomycin, and vinblastine chemotherapy as initial treatment. Two patient received cisplatin, bleomycin, and etoposide and one the seven drug combination POMB/ACE (cisplatin, vincristine, methotrexate, bleomycin actinomycin D, cyclophosphamide, etoposide). ${ }^{3}$ The remaining seven patients were moribund or elderly at diagnosis and received either no or attenuated treatment.

Eight of the nine patients who died with seminoma had either bulky abdominal disease or lung metastases at presentation. The remaining patien developed late lung relapse after a stage IIB tumour had been managed with radiotherapy alone. Seven patients were managed by extensive radiotherapy. Only three received chemotherapy. Two patients were elderly ( 69 and 80 years) and did not receive treatment.

\section{TREATMENT RELATED DEATHS}

There were 12 patients whose deaths were considered to be the consequences of treatment. Table III summarises the details. 
Two patients died at home in between courses of chemotherapy. A 75 year old patient who originally had a stage IIA undifferentiated malignant teratoma treated with $4600 \mathrm{cGy}$ (rads) to the para-aortic nodes developed lung metastases 30 months later. After one course of vincristine and bleomycin he died at home 10 days after discharge. A second patient, aged 43, approaching remission with a stage IV intermediate teratoma, died 12 days after going home, having received his third course of chemotherapy with BEP (bleomycin, etoposide, cisplatin). No specific cause was found at necropsy.

There were four deaths from incidental causes. Three were in comparatively elderly patients (ages 59, 72, and 73) with stage I seminoma treated with irradiation to the para-aortic nodes. The causes of death were myocardial infarction, pneumonia, and cerebral vascular accident, respectively. The fourth patient was 47 at diagnosis with a stage IIC seminoma treated with abdominal irradiation and five courses of etoposide and cisplatin. Six months after complete remission he died of septicaemia as a result of septic arthritis of the hip. There was no evidence of bone metastasis.

\section{Discussion}

A retrospective study of mortality has inherent inaccuracies that stem from variation in the reliability of medical records. Particular difficulty arises in the clinical description of circumstances around the time of death. Postmortem examinations are performed in only a few patients who die with cancer. Despite these limitations the patients were categorised as accurately as possible.

The overall mortality in this series was $10 \cdot 8 \%$. A study of similar patients treated during $1976-80$ recorded a mortality of $24 \%$. This reflects the recent improvements in the management of testicular cancer.

Thirty four deaths in patients with progressive disease form the largest group in the study. Of 25 patients with teratoma, only four did not have detectable pulmonary metastases at presentation. There were no deaths recorded in patients presenting with stage I or IIA disease. This confirms the excellent prognosis for teratoma treated at an early stage. Fifteen patients received chemotherapy with PVB (cisplatin, vinblastine, bleomycin) initially, 10 of these subsequently receiving salvage regimens containing etoposide. Failure of the PVB combination to control advanced bulky teratoma accords with original studies, where complete remission with PVB was obtained in only $60 \%$ of such patients.

Since the bleomycin, etoposide, and cisplatin regimen (BEP) was shown to have significant advantages in comparison with PVB, both from the response rate in bulky disease as well as in its lower toxicity, BEP has been the treatment of choice in all centres in East Anglia and Trent. Two patients in this series died despite initial chemotherapy with BEP. One refused treatment until he was virtually moribund, and the other had received extensive radiotherapy and was unable to have regular courses because of severe myelosuppression. Large volume radiotherapy is not now considered part of the correct management of teratoma.

Five patients with teratoma were not given treatment, either because of age at presentation or because they were in a moribund state with cerebral metastases and advanced disease. The recorded success of treatment of brain metastases with BEP now means that these patients should be treated aggressively and still have some chance of successful outcome. ${ }^{8}$

TABLE II-Deaths from progressive disease

\begin{tabular}{|c|c|c|c|c|c|c|c|c|c|c|c|}
\hline \multirow{2}{*}{$\begin{array}{l}\text { Histological } \\
\text { diagnosis }\end{array}$} & \multirow{2}{*}{$\begin{array}{c}\text { No } \\
\text { of } \\
\text { patients }\end{array}$} & \multirow{2}{*}{$\begin{array}{l}\text { Mean } \\
\text { age } \\
\text { (years) }\end{array}$} & \multicolumn{4}{|c|}{ Tumour stage } & \multirow{2}{*}{$\begin{array}{c}\text { Mean } \\
\text { survival } \\
\text { (months) }\end{array}$} & \multirow{2}{*}{$\begin{array}{c}\text { No } \\
\text { given } \\
\text { radiotherapy }\end{array}$} & \multicolumn{2}{|c|}{ Radiotherapy sites } & \multirow{2}{*}{$\begin{array}{c}\text { No of patients } \\
\text { given chemotherapy } \ddagger \\
\text { (mean No of courses per pątient) }\end{array}$} \\
\hline & & & I & II & III & IV & & & Para-aortic nodes & Othert & \\
\hline MTU & 16 & $36 \cdot 6$ & 0 & 2 & 0 & 14 & $7 \cdot 7$ & 3 & 3 & - & $12(4 \cdot 7)$ \\
\hline MTT & 5 & $34 \cdot 4$ & 0 & 0 & 0 & 5 & $10 \cdot 0$ & 1 & 1 & 1 & $5(7 \cdot 8)$ \\
\hline MTI & 4 & $32 \cdot 2$ & 0 & 0 & 2 & 2 & $18 \cdot 6$ & 2 & 2 & 1 & $4(6.5)$ \\
\hline SEM & 9 & $55 \cdot 2$ & 0 & 6 & 0 & 3 & $11 \cdot 6$ & 7 & 7 & 6 & $3(1)$ \\
\hline
\end{tabular}

${ }^{\star} M T U=$ Malignant teratoma, undifferentiated. $M T T=$ Malignant teratoma, trophoblastic. $M T I=$ Malignant teratoma, intermediate. SEM=Seminoma.

fOther sites were lung (one case), spine (one), brain (two), supraclavicular fossa (three), mediastinum (three).

†The following regimens were used (number of courses in parentheses): PVB (76), BEP (six), POMB (nine), ACE (15), BEVIP (three), EP (one), PVA (three), ED+M (one), EP+I (one), $\mathrm{E}+\mathrm{I}$ (one), VB (three). Single drug courses were etoposide (three), cyclophosphamide (one), JM8 (one), vinblastine (one), actinomycin D (one), methotrexate (two), chlorambucil (one) $(\mathrm{P}=$ Cisplatin. $\mathrm{V}=$ Vinblastine. $\mathrm{B}=$ Bleomycin. $\mathrm{E}=$ Etoposide. $\mathrm{M}=$ Methotrexate. $\mathrm{O}=$ Vincristine. $\mathrm{I}=$ Ifosfamide. $\mathrm{A}=\mathrm{Actinomycin} \mathrm{D}$. $\mathrm{C}=\mathrm{Cyclophosphamide}$. $\mathrm{D}=\mathrm{DT} \mathrm{D} \mathrm{C}$.

TABLE III-Treatment related deaths

\begin{tabular}{|c|c|c|c|c|c|c|c|c|c|}
\hline \multirow[b]{2}{*}{$\begin{array}{l}\text { Case } \\
\text { No }\end{array}$} & \multirow[b]{2}{*}{$\begin{array}{c}\text { Age } \\
\text { (years) }\end{array}$} & \multirow[b]{2}{*}{$\begin{array}{c}\text { Histological } \\
\text { diagnosis }^{\star}\end{array}$} & \multirow[b]{2}{*}{$\begin{array}{l}\text { Tumour } \\
\text { stage }\end{array}$} & \multirow[b]{2}{*}{$\begin{array}{c}\text { Survival } \\
\text { (months) }\end{array}$} & \multicolumn{2}{|l|}{ Radiotherapy } & \multirow[b]{2}{*}{ Chemotherapy† } & \multirow[b]{2}{*}{ Progressł } & \multirow[b]{2}{*}{ Cause of death } \\
\hline & & & & & Site & $\begin{array}{l}\text { Dose } \\
\text { (cGy) }\end{array}$ & & & \\
\hline 1 & 71 & MTU & IV & 2 & - & - & $\mathrm{PVB} \times 2$ & PR & Hypokalaemia, septicaemia \\
\hline 2 & 34 & MTU & IIB & 9 & Para-aortic nodes & 5000 & $\mathrm{PVB} \times 2$ & $\mathrm{CR}$ & Neutropenic septicaemia \\
\hline 3 & 25 & MTU & IIB & 15 & Para-aortic nodes, pelvis & 4250 & $\mathrm{PVB} \times 3$ & PD & Neutropenic septicaemia, pneumonia \\
\hline 4 & 31 & MTT & IV & 4 & - & - & $\mathrm{PVB} \times 5$ & PD & $\begin{array}{l}\text { Staphylococcus aureus septicaemia, thrombocytopenic } \\
\text { cerebral bleed }\end{array}$ \\
\hline 5 & 37 & MTU & IV & 2 & - & - & $\mathrm{PVB} \times 2$ & PR & $\begin{array}{l}\text { One week after chemotherapy grand mal convulsion } \\
\text { associated with vomiting and renal failure. Gram } \\
\text { negative septicaemia and meningitis found at } \\
\text { necropsy }\end{array}$ \\
\hline 6 & 57 & SEM & IIC & 22 & Para-aortic nodes, pelvis & 4000 & $\mathrm{BEP} \times 5$ & PR & Renal failure during fifth course of BEP \\
\hline 7 & 32 & SEM & IIC & 14 & Para-aortic nodes, pelvis & 3000 & $\mathrm{PVB} \times 8, \mathrm{POMB} \times 1$ & PR & $\begin{array}{l}\text { Renal failure during POMB despite relief of possible } \\
\text { ureteric obstruction }\end{array}$ \\
\hline 8 & 42 & MTT & IV & 6 & - & - & $\mathrm{BEP} \times 6$ & $\mathrm{CR}$ & $\begin{array}{l}\text { Massive intracerebral bleed at site of previous } \\
\text { metastases, thrombocytopenia }\end{array}$ \\
\hline 9 & 68 & MTT & IV & 4 & - & - & $\mathrm{PVB} \times 4, \mathrm{ACE} \times 1$ & PR & $\begin{array}{l}\text { Fracture of left temporal bone after fall followed by } \\
\text { rapid intracerebral bleed due to thrombocytopenia }\end{array}$ \\
\hline 10 & 37 & MTT & IV & 4 days & - & - & $\mathrm{PVB} \times 1$ & - & $\begin{array}{l}\text { Acute respiratory distress, pulmonary oedema } 28 \text { hours } \\
\text { after first injection of cisplatin (lung metastasis } \\
\text { present) }\end{array}$ \\
\hline 11 & 20 & MTT & IV & 3 days & - & - & $\mathrm{BEP} \times 1$ & - & $\begin{array}{l}\text { Acute respiratory distress, pulmonary oedema } 36 \text { hours } \\
\text { after first injection of cisplatin (lung metastasis } \\
\text { present) }\end{array}$ \\
\hline 12 & 28 & SEM & I & 17 & Para-aortic nodes & 6000 & - & CR & Irradiation enteritis after miscalculated radiation dose \\
\hline
\end{tabular}

${ }^{\star} M T U=$ Malignant teratoma, undifferentiated. $M T T=$ Malignant teratoma, trophoblastic. $S E M=$ Seminoma.

$+\mathrm{P}=$ Cisplatin. $\mathrm{V}=$ Vinblastine. $\mathrm{B}=$ Bleomycin. $\mathrm{E}=$ Etoposide. $\mathrm{O}=$ Vincristine. $\mathrm{M}=$ Methotrexate. $\mathrm{A}=$ Actinomycin. $\mathrm{D} . \mathrm{C}=\mathrm{Cyclophosphamide}$.

$\neq \mathrm{PR}=$ Partial response. $\mathrm{CR}=$ Complete response. $\mathrm{PD}=$ Progressive disease

Conversion: SI to traditional units - Radiotherapy dose: $1 \mathrm{cGy}=1 \mathrm{rad}$. 
Seven of the nine patients who died of progressive seminoma had received extensive irradiation. Chemotherapy was used as primary treatment in only three patients. The high mean age in this group $(55 \cdot 2$ years) may in part explain the reluctance to use aggressive regimens; indeed, two patients received no treatment at all on account of age (69 and 80 years). It is now clear that the response of seminoma to BEP or single agent cisplatin is excellent and that this should be regarded as the treatment of choice for metastatic seminoma except in stage IIA disease. Concomitant low dose irradiation to sites of bulky tumour deposits is still recommended in view of the sensitivity of seminoma to irradiation.

Twelve patients were considered to have died from treatment related problems. In five patients presumptive or proved septicaemia contributed to death. All five had widespread teratoma and were being treated with PVB. Two had received radiotherapy which increased the degree of myelosuppression. As mentioned above, radiotherapy should be avoided in teratoma. The incidence of septicaemia with the BEP combination is lower than with PVB as etoposide is less myelosuppressive than vinblastine. No deaths due to septicaemia were recorded with this combination. The cause of death in the two patients who died suddenly while receiving chemotherapy was not apparent. Possible factors include electrolyte disturbances after continued vomiting at home, septicaemia, intracerebral haemorrhage, and renal failure. These deaths should be preventable, and patients should not be sent home after a course of chemotherapy unless vomiting has stopped and electrolyte imbalance is considered unlikely. The general practitioner should be vigilant, and rapid 24 hour access to oncological advice should be readily available.

In view of the well recognised renal toxicity of cisplatin it is perhaps surprising that renal failure contributed to the cause of death in only three patients. The forced diuresis regimen appears adequate to protect the kidneys, but hypokalaemia induced by this contributed to death in one patient. Should renal failure develop there should be no question about the need for dialysis. Unfortunately, cisplatin chemotherapy must be stopped and alternative regimens substituted. New cisplatin analogues (such as carboplatin) which are less toxic to the kidneys will soon be available, and so the mortality from renal failure and forced diuresis should be eliminated.

The management of testicular cancer represents one of the greatest achievements in clinical oncology of the past few years. The optimal treatment of this disease depends on the successful integration of several clinical disciplines. We believe that this is the first detailed analysis of mortality in a regional hospital setting. From our findings we make the following recommendations.

(1) Age or general medical problems should not preclude attempts at using combination chemotherapy in this highly responsive disease.

(2) There is no place for extensive field radiotherapy (inverted $\mathrm{Y}$ and mediastinal irradiation) in patients with stage II or III testicular tumours. This leads to profound and sometimes lethal myelosuppression should chemotherapy subsequently be necessary.

(3) The PVB regimen (cisplatin, vinblastine, bleomycin) should be abandoned in favour of a combination containing etoposide, of which BEP (bleomycin, etoposide, cisplatin) is the most widely used.

(4) Chemotherapy with a regimen containing cisplatin should be used as primary treatment for patients with bulky or extensive seminoma instead of large field irradiation. Radiotherapy should be confined to sites of bulky disease reduced in volume by chemotherapy.

(5) Patients with extensive lung metastases should receive reduced dose chemotherapy for their first course to avoid triggering a respiratory distress syndrome due to tumour lysis. A careful watch over respiratory function should be maintained.

(6) Renal problems due to cisplatin are easily avoided in most patients by giving a forced diuresis, which should be discontinued only after vomiting has stopped. Patients should seek medical advice if vomiting or diarrhoea develops after discharge home.

(7) Vigilance by the patient's general practitioner is mandatory both during and after chemotherapy so that serious infections or metabolic problems may be recognised early. Twenty four hour access to oncological advice is essential.

We thank our clerical, medical, and nursing colleagues for their help. We are particularly indebted to the staff of the cancer registries in the two regions, and to the trustees of the Huntingdon and Cambridge Cancer Research Trust for financial support.

\section{References}

1 Ellis M, Sikora K. Advances in the management of testicular cancer. In: Mathe G, ed. Therapeutic trials in oncology. Geneva: Bioscience, 1985.

Medical Research Council Working Party on Testicular Tumours. Prognostic factors in advanced non-seminomatous germ cell testicular tumours: results of a multicentre study. Lancet 1985;i: $8-11$.

3 Newlands ES, Begent RH, Rustin GJ, Parker D, Bagshawe KD. Further advances in the management of malignant teratomas of the testis and other sites. Lancet 1983;i:948-51.

4 Peckham M. Management of testicular tumours. London: Edward Arnold, 1981.

5 Pugh RCB, Cameron KM. Teratoma. In: Pugh RCB, ed. Pathology of the testis. Oxford: Blackwell, 1976:199.

6 Peckham MJ, McElwain TJ, Barrett A, Hendry WF. Combined management of malignant teratoma of the testis. Lancel 1979;ii:267-70.

7 Einhorn LH, Donohue JP. Cisdiamminodichloroplatinum, vinblastine and bleomycin in disseminated testicular cancer. Am f Med 1977;87:293-301.

8 Bagshawe KD, Begent RHJ, Glaser MG, Makey AR, Newlands ES, Reynolds KW. Clinics in Oncology 1983;2:183-213.

(Accepted 8 fanuary 1986)
I have received promotional literature advocating giving pregnant women zinc supplements as well as iron. I have heard that zinc deficiency may be a factor in anorexia nervosa but do you think routine zinc supplements should be given to normal pregnant women?

In animals experimental zinc deficiency has been associated with teratogenesis and pregnancy complications, and in people congenital abnormalities have been reported with acrodermatitis enteropathica, a rare disease of zinc deficiency. ${ }^{1}$ Plasma zinc concentrations fall in normal pregnancy, ${ }^{2}$ and may be particularly low in women with pre-eclampsia ${ }^{3}$ or an encephalic fetus. ${ }^{4} \mathrm{~A}$ possible association between low plasma zinc concentrations and fetal growth retardation ${ }^{2}$ has not been confirmed, ${ }^{\prime}$ but fetal growth retardation has been associated with a low concentration of zinc in peripheral blood leucocytes 1 - a relation that is only partly explained by the finding that smokers have low white cell zinc concentrations. ${ }^{5}$ Low zinc concentrations may merely indicate poor general nutrition, ${ }^{5}$ and the effect of zinc supplements remains unproved.

Because zinc and iron compete with each other for absorption, ${ }^{1}$ it has been suggested that iron supplements may cause zinc depletion, ${ }^{5}$ and it seems irrational to combine zinc and iron supplements in the same preparation. Of the few trials of zinc supplementation in pregnancy, only one has been controlled, and it showed no effect on the outcome of pregnancy except for a slightly lower incidence of pre-eclampsia in women who had taken zinc compared with controls. ${ }^{6}$ In that trial pregnancy outcome was better among women who complied with the treatment regimen in both control and supplemented groups. Other trials of zinc supplementation are now in progress, ${ }^{5}$ but at present there is no good reason to give routine zinc supplements to pregnant women. - JAMES OWEN DRIFE, senior lecturer in obstetrics and gynaecology, Leicester.

1 Meadows NJ. Zinc in pregnancy. Maternal and Child Health 1984;9:150-3.

2 Jameson S. Effects of zinc deficiency in human reproduction. Acta Med Scand 1976;supp 593:1-89. 3 Zimmerman AW, Dunham BS, Nochimson DJ, Kaplan BM, Clive JM, Kunkel SL. Zinc transport in pregnancy. Am $\mathcal{J}$ Obstet Gynecol 1984;149:523-9.

Buamah PK, Russell M, Bates G, Ward AM, Skillen AW. Maternal zinc status: a determination of central nervous system malformation. Brf Obstet Gynaecol 1984;91:788-90.

Simmer K, Thompson RPH. Maternal zinc and intrauterine growth retardation. Clin Sci 1985;68:395-9.

6 Hunt IF, Murphy NJ, Cleaver AE, et al. Zinc supplementation during pregnancy: effects on selected blood constituents and on progress and outcome of pregnancy in low-income women of Mexican descent. Am f Clin Nutr 1984;40:508-21.

7 Hytten FE. Do pregnant women need zinc supplements? Br f Obstet Gynaecol 1985;92:873-4. 